Recibido: 15 noviembre 2021 | Aceptado: 30 noviembre 2021 | Publicado: 1 diciembre 2021

Cita: González Riffo, J. (2021). Funciones de la atenuación en el registro académico formal escrito: el caso del derecho y los comentarios de jurisprudencia en Chile. Normas, 11 (1), 84-99. doi: https://dx.doi.org/10.7203/Normas.v11i1.21973

\title{
Funciones de la atenuación en el registro académico formal escrito: el caso del derecho y los comentarios de jurisprudencia en Chile ${ }^{1}$
}

FUNCTIONS OF MITIGATION IN FORMAL ACADEMIC WRITTEN REGISTERS: THE CASE OF LAW AND JURISPRUDENCE COMMENTARIES IN CHILE

\author{
Javier González Riffo \\ Universidad Católica Silva Henríquez
}

Resumen

La atenuación es entendida como un fenómeno retóricocomunicativo cuyo empleo reduce la fuerza ilocutiva de los enunciados con el fin de resguardar la imagen de los interactuantes $y$, consecutivamente, alcanzar con éxito las metas previstas (Albelda, 2016; Cestero y Albelda, 2020). Durante los últimos años, este fenómeno ha sido atendido especialmente a propósito del lenguaje oral en géneros discursivos preferentemente coloquiales, pero recientemente se ha apreciado un interés por estudiarlo en diversos géneros orales y escritos de carácter académico. En este contexto, este artículo tiene por objetivo describir el funcionamiento de recursos de atenuación presentes en un género discursivo disciplinar escasamente descrito: los comentarios de jurisprudencia. Con este propósito, se hace uso de herramientas de lingüística de corpus para, por una parte, recopilar 18 comentarios de jurisprudencia (97772 palabras en total) publicados durante los últimos 10 años en revistas indexadas chilenas y de corriente principal en Derecho, y, por otra parte, para automatizar la búsqueda de los atenuadores, lo cual se complementó con un análisis inferencial. Los resultados sugieren una relación entre el empleo de atenuadores, la expresión de interpretaciones jurídicas y la evaluación del comportamiento de miembros de la comunidad disciplinar, en especial aquellos que ostentan poder social y simbólico.

PALABRAS CLAVE: atenuación, pragmalingüística, registro académico, lingüística de corpus, comentario de jurisprudencia
Abstract

Mitigation is understood as a rhetorical-communicative phenomenon whose use reduces the illocutionary force of utterances in order to protect the image of the interactants and, consequently, to successfully achieve the intended goals (Albelda, 2016; Cestero and Albelda, 2020). During the last few years, this phenomenon has been addressed especially regarding oral language in colloquial discourse genres, but recently there has been an interest in studying it in various oral and written academic genres. In this context, the aim of this article is to describe the functioning of mitigating resources found in a scarcely described disciplinary genre: case law commentaries. For this purpose, corpus linguistics tools are used to, on the one hand, collect 18 case law commentaries (97772 words in total) published during the last 10 years in Chilean indexed and mainstream law journals, and, on the other hand, to automate the search for mitigators, which was complemented with an inferential analysis. The results suggest a relationship between the use of mitigators, the expression of legal interpretations and the evaluation of the behavior of members of the disciplinary community, especially those who hold social and symbolic power.

KEY WORDS: mitigation, pragmalinguistics, academic register, corpus linguistics, case law commentary

\footnotetext{
1 Este trabajo se enmarca en el proyecto de investigación «La atenuación lingüística en el español chileno: enfoque pragmalingüístico y sociopragmático» (ANID/CONICYT Fondecyt Regular 1200003).
} 


\section{INTRODUCCIÓN}

En los estudios de pragmalingüística en español, ha habido un especial interés por las formas y las funciones de la atenuación. Entendida como una estrategia retóricacomunicativa por medio de la cual los hablantes matizan la fuerza ilocutiva de sus actos de habla con el objetivo de proteger o mejorar su imagen y la de sus interlocutores (Albelda, 2016; Cestero y Albelda, 2020), su estudio se ha centrado especialmente en la conversación coloquial oral (v. gr. Briz, 2001) y su aproximación sociolingüística variacionista (v. gr. Cestero, 2017; Samper, 2018; Albelda y otros, 2020), también a propósito de su manifestación oral.

La descripción de las dimensiones de la atenuación, sin embargo, no se agota únicamente en el estudio de su expresión oral. Recientemente ha crecido el interés por estudiar este fenómeno en su dimensión discursiva a través de diversos géneros distintos a la conversación coloquial, incluso escritos. Evidencia de esto último es la reciente publicación de Atenuación e intensificación en géneros discursivos (Albelda y Mihatsch, 2017). Asimismo, otros trabajos han volcado su interés al estudio de la atenuación en practicas discursivas inscritas en entornos institucionales, entre ellos, en discursos académicos ( $v$. gr. Hyland, 1996; Martín-Martín, 2008; Alonso-Almeida, 2015)

La premisa basal que se desprende de la literatura es que el uso de atenuadores está mediado por el fin que persiguen los hablantes en la interacción. Estos fines son, por cierto, sensibles a las prácticas culturales en que se enmarca el intercambio comunicativo (Cestero y Albelda, 2012). De esta forma, así como en la conversación coloquial oral los atenuadores pueden desempeñar funciones determinadas en una comunidad de habla concreta (cf. Briz y Albelda, 2013; Albelda, 2016), en el análisis de prácticas discursivas de ciertas comunidades disciplinares aquellas funciones podrían ser distintas.

En el contexto de la escritura disciplinar, en especial de textos que circulan públicamente en la comunidad académica, el uso de atenuadores es capital (Hyland, 1998). Siguiendo a Morales, Cassany y González (2007), el empleo de atenuadores se utiliza para dar cuenta del desarrollo progresivo de un nicho investigativo, para evitar críticas derivadas de las afirmaciones del autor, y para proyectar deferencia hacia los colegas. Cualquiera sea el caso, los atenuadores se relacionan con la imagen social toda vez que el texto mismo expone la imagen de su autor y, a la vez, la de los demás miembros de la comunidad disciplinar al incluir sus voces a modo de referencias.

Una comunidad disciplinar cuyas prácticas discursivas no han sido suficientemente estudiadas es la del Derecho. Como tal, conforma una comunidad discursiva (Swales, 1990), ya que sus miembros comparten objetivos comunes y se comunican por medio de cadenas de géneros (Swales, 2004) que también tienen sus propias convenciones discursivas. Así, considerando que los géneros discursivos no solo vinculan a los miembros de una determinada cultura por su pertenencia a esa misma comunidad (Bajtín, 1985; Martin y Rose, 2008), sino que también cumplen un rol formativo al organizar los grupos sociales (Bazerman, 2012), el estudio de fenómenos asociados a la construcción de sus prácticas discursivas también puede serle útil a los programas de alfabetización académica 
universitarios. Así, el análisis de sus géneros disciplinares propios, concretamente sus prácticas de escritura, ilustraría las dinámicas de la comunidad que los produce (Bazerman, 1988; Haas, 1994; Carlino, 2006).

En este contexto, en el presente trabajo se pretende describir el funcionamiento de los atenuadores en comentarios de jurisprudencia publicados en revistas académicas chilenas de Derecho. Para dar cumplimiento a este objetivo, se realiza un análisis inductivo que consiste en identificar los atenuadores para luego elaborar una taxonomía de funciones a partir de patrones observables en la muestra analizada. El corpus recolectado se compone de comentarios de jurisprudencia publicados en diversas revistas académicas de la disciplina. Para esto, se utilizan herramientas de lingüística de corpus, aspecto que en el estudio de la atenuación pragmalingüística no se ha explotado suficientemente.

\section{MARCO TEÓRICO}

\subsection{La atenuación pragmática}

La atenuación constituye un fenómeno pragmático (Briz, 2001). En efecto, por medio del uso de recursos atenuantes los hablantes reducen la fuerza ilocutiva de sus enunciados (Briz, 2001; Caffi, 1999) o mitigan las obligaciones asumidas en la interacción (MeyerHermann, 1988). Se trata, entonces, de una «estrategia retótico-pragmática originada por necesidades de protección de imagen (propia o ajena), para proteger, suavizar y reparar los posibles efectos perjudiciales para el adecuado desarrollo de la comunicación» (Cestero y Albelda, 2020, p. 940). El empleo de atenuadores, si bien lingüísticamente implican una reducción del compromiso del hablante ante lo dicho, socialmente significa acercamiento (Albelda, 2016), pues su uso permite resguardar la armonía en la interacción al proteger la imagen pública de los interactuantes. En este sentido, si bien el uso de atenuadores puede vincularse con la cortesía lingüística, no todo uso de atenuador es a la vez un recurso cortés (Briz y Albelda, 2013).

La literatura suele confrontar a la atenuación con la intensificación, con la cual establecería un continuum (cfr. Meyer-Hermann, 1988; Caffi, 1999). Así, ambos fenómenos tendrían consideraciones sociales, en que se vinculan con la armonía interpersonal de la interacción; y argumentativas, en que se relacionan con la posición de los hablantes con respecto a lo que tratan en la interacción (Briz, 2017). Sin embargo, algunos trabajos sugieren que esta diferenciación no es del todo taxonómica (cf. Monjour, 2017; González Riffo y Guerrero González, 2017; González y García, 2017).

Con respecto a las funciones que cumplen los atenuadores en las conversaciones orales, Briz y Albelda (2013) ofrecen una taxonomía, la cual ha sido retomada y detallada por otros autores (v. gr. Cestero, 2020; Cestero y Rodríguez, 2021). En esta, los autores plantean tres funciones que se diferencian según la afección a la propia imagen, a la imagen del interlocutor o a la prevención ante potenciales amenazas. Si bien en la propuesta de Briz y Albelda (2013) se alude a una función 0, caracterizada por la no implicación de la imagen en el uso de atenuadores, Albelda (2016) y Cestero y Albelda (2020) argumentan que la atenuación parece siempre estar relacionada con la imagen social. Briz y Albelda (2013) 
también describen una serie de recursos atenuantes para el español y el portugués y precisan que estos son multifuncionales; es decir, que cada recurso puede cumplir más de una de las funciones identificadas, razón por la cual el análisis no debe obviar el contexto interactivo concreto.

En el contexto de la comunicación académica, una propuesta importante es la que realiza Hyland (2005). Para el autor, "todo uso del lenguaje se relaciona con contextos sociales, culturales e institucionales”' (p. 174). Por esta razón, atenuadores e intensificadores hedges y boosters- se relacionan con la expresión de la actitud: juicios o evaluaciones de probabilidad epistémica y estimaciones. En esta línea, los recursos de atenuación corresponden a estrategias comunicativas que manipulan el grado de compromiso con lo dicho con el propósito de lograr el cumplimiento efectivo de las metas personales previstas. Esto, con el objetivo de transmitir modestia, precisión, cuidado y certeza, valores que serían preciados en la escritura disciplinar (Hyland, 1996).

\subsection{Los géneros discursivos en el Derecho: el comentario de jurisprudencia}

La literatura recoge la importancia que tiene el lenguaje para el campo del Derecho. Siguiendo a Conley y O'Barr (2005), entre ley y lenguaje existe una suerte de dependencia, pues la primera se realiza y actualiza por medio del segundo. Por esto, no es de extrañar que en la construcción de ese campo disciplinar los géneros discursivos cumplan un rol no solo comunicativo, sino también formativo, al ser fácilmente reconocibles por los miembros de su comunidad (Bajtín, 1985).

En línea con lo anterior, los géneros por medio de su circulación vinculan a los participantes que participan de la comunidad disciplinaria. En el campo del Derecho, son tres los principales participantes expertos: Ios litigantes, los académicos y los funcionarios (Agüero, 2014). Estos conforman lo que conocemos como comunidad jurídica.

Aguilar (2017) sistematiza ciertos géneros académicos escritos jurídicos útiles para los procesos de alfabetización académica. Si bien su propuesta tiene como foco la aplicación de los géneros con fines de enseñanza, esta sistematización también revela en parte cuáles son los discursos que circulan en la comunidad jurídica. En esta línea, la autora propone cuatro macrocategorías, que corresponden a los informes en derecho, los escritos forenses, la resolución judicial y los contratos. Las funciones discursivas asociadas tienen relación con objetos jurídicos y las diversas etapas de un proceso judicial.

Un género escasamente descrito por la literatura e interesante por su carácter argumentativo corresponde al comentario de jurisprudencia -también denominado comentario de sentencia o comentario de legislación-. Si bien su descripción en tanto género discursivo corresponde a una tarea aún no resuelta, cabe precisar que la comunidad jurídica lo reconoce al menos como un tipo de texto. Evidencia de esto es el tratamiento que distintas revistas académicas especializadas del Derecho le otorgan en sus normas editoriales, destacando su diferenciación frente a otros géneros como el

2 Traducción propia. Cita original: «... all language use is related to specific social, cultural and institutional context». 
artículo de investigación y el ensayo. Este reconocimiento por cierto revela un acuerdo compartido por la comunidad, característica de un género discursivo (Bazerman, 1998).

El comentario de jurisprudencia corresponde, en términos de Tolchinsky (2013), a un género científico no académico, aunque esta catalogación es discutible, dada su circulación en entornos precisamente académicos como lo son las revistas de especialidad editadas por instituciones de educación superior. Su objetivo semiótico corresponde a plantear «una valoración crítica de una sentencia, línea jurisprudencial o norma concreta» (Tolchinsky, 2013: 81). Esto, a partir de una reflexión jurídica, para la cual se hace uso de la jurisprudencia. Cabe destacar que la teoría en el campo del Derecho, así como también el tratamiento e interpretación de la norma se actualiza precisamente a través de las sentencias dictadas antes incluso que por el cambio escrito de la ley. Esta concepción pone en relieve la consideración de los géneros discursivos como práctica social (Fairclough, 2013). De ahí entonces la relevancia de la circulación de estos comentarios, ya que estos precisan los patrones que se siguen y las discusiones que se abren en la discusión jurídica local de un sistema jurídico determinado.

Por último, es importante notar como descripción de los comentarios de jurisprudencia que estos se componen a partir de diversas etapas, cada una con fines específicos y secuencias asociadas. Así, es posible identificar en ellas narraciones cronológicas de los hechos previos a la sentencia, identificación de los participantes involucrados en el evento que causa la acusación y su participación en el evento jurídico, discusiones jurídicas en torno a la sentencia y una evaluación global de esta y su impacto en el contexto del campo. Esto último pone en relieve un importante carácter argumentativo en que el escritor del comentario, ya sea como profesional y/o como académico, establece un diálogo crítico con los distintos estamentos del sistema jurídico local.

\section{Metodología}

\subsection{Compilación del corpus}

El corpus corresponde a un conjunto de comentarios de jurisprudencia publicados en la web y cuya circulación se realice en medios de divulgación académica, concretamente en revistas disciplinares de código abierto. Esto, considerando que, al ser textos públicos y evaluados por pares, sirven como textos modélicos para los miembros de la comunidad disciplinar, lo que también incide en la fijación estructural del género. Se trata, en consecuencia, de un corpus monolingüe en español, especializado y que se compone de fuentes públicas en la web. Se espera que este corpus sea útil para el estudio del lenguaje jurídico en general, razón por la cual su diseño, como se detalla a continuación, permite futuras ampliaciones y modificaciones.

Para la compilación, se utilizó la herramienta BootCat. Las palabras 'semilla' utilizadas para la búsqueda de los textos debían ser lo suficientemente generales como para también tener una alta frecuencia en otros comentarios de jurisprudencia, así como también su contenido semántico debía estar altamente relacionado con el campo del Derecho. En este contexto, previamente se realizó una exploración en cinco comentarios de jurisprudencia publicados 
durante 2019 en la Revista Chilena del Derecho, de indización Scopus. Específicamente, se analizó por medio de Sketch Engine cuáles eran los quince sustantivos de mayor frecuencia que cumpliesen con los criterios precisados. Con posterioridad, los resultados fueron triangulados con dos abogados que se desempeñan en tareas académicas con el objetivo de discernir cinco palabras semilla, las cuales se utilizaron luego en la búsqueda de BootCat.

Las palabras semilla finalmente elegidas fueron 'derecho, 'daño', 'ley', 'protección' e 'incumplimiento'. Adicionalmente, se añadió 'comentario de jurisprudencia' para facilitar el posterior filtro por género discursivo. Esta unidad pluriverbal fue la única que se repitió en todas las combinaciones entre unidades, lo que dio como resultado un total de diez tuples (combinaciones de palabras semillas). Se configuró el software de forma tal que la búsqueda se realizase a partir de la plataforma Scielo para asegurar el carácter académico de los textos resultantes.

Por último, con los resultados se procedió a filtrar manualmente los textos. En este proceso se aplicaron tres criterios: (1) que todos los textos efectivamente fueran explícitamente identificados como comentario de jurisprudencia o comentario de sentencia por parte del comité editorial de la revista que los aloja; (2) que estuviesen escritos íntegramente en español, salvo por segmentos de discurso referido y por segmentos de resumen y palabras clave; (3) que hayan sido publicados desde 2010 en adelante; y (4) que en efecto la afiliación institucional de sus autores se corresponda con universidades chilenas.

El total de documentos recolectados correspondió a 18 comentarios de jurisprudencia (97772 palabras en total). Debido a que el proceso editorial previo a la publicación de estos textos salvaguarda la integridad de la información sensible vertida en esos documentos, no fue necesario un proceso de limpieza relativo a ello, pero sí se conmutaron todas las citas textuales por la expresión 'CITA' para que los buscadores no analizasen tales textos. Por último, cada texto de la muestra fue rotulado con la siguiente codificación: 'CJ', para indicar el género, en caso de en el futuro ampliarse este corpus; seguido por una barra baja y un número de tres dígitos, comenzando por '001', que indica el orden correlativo del texto con respecto al corpus; y otra barra baja seguida de dos dígitos que hacen alusión al año de publicación del texto. Esta información se precisa también como encabezado de cada archivo.

\subsection{Procesamiento del corpus}

Como hemos señalado, el objetivo concreto de nuestra pesquisa es describir el funcionamiento de los recursos de atenuación presentes en comentarios de jurisprudencia. Sin embargo, el corpus pretende ser útil para indagaciones de diversa naturaleza. Por esta razón, y con el objetivo de que pueda ser explotado por diversas herramientas informáticas, los documentos que lo conforman se encuentran en formato .docx.

Para esta investigación, concretamente se siguieron los siguientes pasos metodológicos: primero, todos los comentarios de jurisprudencia se segmentaron manualmente en oraciones. Como ha sido de esperar, la mayor parte de estas corresponden a oraciones 
complejas; esto es, con presencia de coordinaciones y subordinaciones. En una segunda etapa de segmentación, se procedió a identificar para cada texto las fases del género. Para esto, se realizó una primera exploración sobre cinco comentarios de jurisprudencia que en su conjunto suman 28.049 palabras (28,7\% del total del corpus). De este análisis se determinó la conveniencia de diferenciar entre tres fases, cada una de las cuales se caracteriza por perseguir un objetivo distinto. Estas son las que siguen:

Tabla 1. Sistematización de las etapas del género comentario de jurisprudencia

\begin{tabular}{|c|c|c|c|}
\hline Etapa & & Función enunciativa & $\begin{array}{l}\text { Descripción lingüística general de la } \\
\text { etapa }\end{array}$ \\
\hline $\begin{array}{l}\text { Descripción } \\
\text { fenómeno }\end{array}$ & del & $\begin{array}{l}\text { Describir de forma general el } \\
\text { cuerpo legal cuya aplicación } \\
\text { origina el comentario. }\end{array}$ & $\begin{array}{l}\text { Se trata de una etapa optativa. } \\
\text { Presencia de secuencias descriptivas. }\end{array}$ \\
\hline $\begin{array}{l}\text { Resumen de } \\
\text { hechos }\end{array}$ & los & $\begin{array}{l}\text { Exponer la sentencia que será } \\
\text { analizada, los dictámenes de los } \\
\text { distintos organismos y la } \\
\text { jurisprudencia atingente al } \\
\text { fenómeno comentado. }\end{array}$ & $\begin{array}{l}\text { Presencia de secuencias narrativas en } \\
\text { lo que respecta a la sucesión de } \\
\text { acontecimientos de la sentencia a } \\
\text { analizar. Se identifican los actores } \\
\text { involucrados en la sentencia (las } \\
\text { partes, los tribunales y otras } \\
\text { instituciones). } \\
\text { Presencia de secuencias descriptivas } \\
\text { relativas a la explicación de las } \\
\text { sentencias de los distintos organismos } \\
\text { legales. }\end{array}$ \\
\hline Reflexión critica & & $\begin{array}{l}\text { Relevar conclusiones, } \\
\text { interpretaciones y evaluaciones } \\
\text { que se desprendan del análisis } \\
\text { efectuado. }\end{array}$ & $\begin{array}{l}\text { Presencia de secuencias descriptivas. } \\
\text { Presencia de lenguaje evaluativo, que } \\
\text { por lo general tiene por objeto evaluado } \\
\text { las sentencias de tribunales. }\end{array}$ \\
\hline
\end{tabular}

Luego, de este mismo pilotaje se procedió a realizar un análisis inductivo con el objeto de identificar los recursos de atenuación característicos del género. En esta tarea se consideró como horizonte analítico las categorías propuestas por Briz y Albelda (2013), Cestero (2020) y Cestero y Albelda (2020). A la vez, para comprobar el carácter atenuante de los recursos se hizo uso de las pruebas de ausencia, conmutación y solidaridad propuestas Villalba (2018). Estas implican evaluar si la fuerza ilocutiva de los enunciados se ve afectada -o no- al intercambiar el atenuador por otro (prueba de conmutación) o al suprimirlo (prueba de ausencia). Asimismo, se comprueba si el potencial atenuador se acompaña de otros recursos en la misma oración, en la oración procedente o en la sucesiva (prueba de solidaridad), pues los atenuadores suelen operar en conjunto. Estas pruebas se evaluaron de forma complementaria.

Los recursos de atenuación identificados más comunes fueron los siguientes:

- Usos condicionales del verbo, como en «... puesto que ello constituiría una obligación de hacer que escapa al alcance objetivo del artículo 183 B del CT, así 
como también todas las obligaciones de hacer y las de dar derivadas del cumplimiento por equivalencia de las obligaciones de hacer» (CJ_001_15_36)³.

- Adverbios de posibilidad o probabilidad ante observaciones, como en «De lo dicho hasta acá es posible advertir que la sentencia que comentamos muestra tres cuestiones relevantes que deben comenzar a considerarse tanto por los litigantes como por los tribunales en casos como los que han sido objeto de este comentario» (CJ_002_19_127).

- Verbos modales, como en «... en ninguna parte se refiere a los términos usadas por las Cortes en cuestión, por lo cual estimamos que fallaron en esta parte a lo menos con la nomenclatura usada por las normas ya derogadas» (CJ_005_14_23).

- Marcadores discursivos modalizadores, como en «Al menos tres posturas se distinguen al respecto en doctrina nacional» (CJ_004_17_88).

En cuanto a las impersonalizaciones, Villalba $(2012,2016)$ estudia el valor atenuante de este recurso en juicios orales. La autora precisa que la impersonalización, en sus diversas manifestaciones, puede servir como recurso estratégico en especial para la protección de la propia imagen. En esta pesquisa, sin embargo, no hemos considerado este recurso. Esto, porque en la exploración inicial hemos vislumbrado que en la escritura de estos textos se prefiere un estilo impersonal, siendo las marcas de primera persona llamativas precisamente por su poca frecuencia. De esta forma, concluimos que, al ser una característica relevante en torno al registro de este tipo de género, en la escala de intensidad se posiciona en el punto cero, no marcado.

Con posterioridad, se procedió a la búsqueda de los recursos en la totalidad del corpus. Para esto se utilizó la plataforma Sketch Engine. Se utilizó la herramienta 'concordancia' y, luego, la búsqueda se realizó por lemas, para el caso de los adverbios, marcadores discursivos y verbos morales; mientras que para los condicionales se buscaron las concordancias de los sufijos. Dado el carácter contextual de la atenuación, se realizó una revisión detallada caso a caso considerando las pruebas de Villalba (2018) y el contexto interactivo concreto (Briz y Albelda, 2013). En cuanto a este último, debido a la modalidad escrita de estos textos, se consideraron la oración con presencia del atenuante, la oración precedente y la procedente.

Por último, para determinar el funcionamiento de los atenuadores en el género comentario de jurisprudencia, se realizó un nuevo análisis inferencial siguiendo los preceptos de la teoría empíricamente fundada. Se consideró la propuesta de Figueras (2018) para la interpretación de los resultados. La autora, quien se basa en el trabajo de Spencer-Oatey (2007), postula que, así como las imágenes sociales se corresponden con valores sociales, es posible observar cuáles son aquellos valores reclamados discursivamente que los atenuadores pretenden proteger.

\footnotetext{
${ }^{3}$ El número final corresponde a la oración del texto. Ennegrecido se observa el atenuante sobre el cual se llama la atención.
} 
Debido al carácter descriptivo de este estudio, no se realizaron pruebas estadísticas descriptivas ni inferenciales.

\section{PRESENTACIÓN DE LOS HALLAZGOS Y DISCUSIÓN}

Con el objeto de describir el funcionamiento de los atenuadores en comentarios de jurisprudencia, a continuación, se presentan algunos patrones observados en el análisis del corpus recopilado.

\subsection{Distanciamiento de las partes}

Los atenuadores son utilizados por los autores de los comentarios de jurisprudencia para distanciarse de lo reclamado por los litigantes o de lo declarado por los mismos tribunales de justicia, quienes, como hemos señalado, son actores de la comunidad jurídica. Estas ocurrencias suelen aparecer preferentemente en la etapa de resumen de los hechos, pues es entonces cuando los autores describen los antecedentes de la sentencia. Los siguientes son ejemplos de nuestro corpus:

(1) Por su parte, las demandadas se defendieron alegando la falta de relación causal pues sería el hecho o culpa de la madre lo que permitió el accidente (CJ_015_10_48)4.

(2) La demandada se defiende negando toda responsabilidad pues se trataría de la responsabilidad de un tercero (contratista) (CJ_015_10_117).

En los ejemplos (1) y (2) la voz autoral se distancia concretamente de lo alegado por una de las partes del caso judicial por medio de usos condicionales de los verbos. Este recurso permite reducir el compromiso del comentarista con respecto a la posición o los hechos que alegan las demandadas. En este sentido, los condicionales posibilitan la duda frente al alegato. Este distanciamiento también se evidencia frente a lo que declaran instituciones judiciales como los tribunales de justicia:

(3) A juicio del máximo tribunal, la solidaridad establecida en el artículo 183 B CT no alcanzaría a las obligaciones de hacer, tales como la infracción al deber de seguridad que tiene el contratista sobre sus propios trabajadores, según lo dispuesto en el artículo 184 del CT (CJ_001_15_73).

En el ejemplo (3) se observa el uso del mismo recurso atenuador que en (1) y (2), pero en este se duda del juicio del «máximo tribunal», que corresponde a una de las tres partes involucradas en un juicio (junto con demandados y demandantes o Fiscalía). Específicamente, por medio de «alcanzaría» la voz autoral toma distancia de la interpretación que ha elaborado el máximo tribunal sobre el artículo citado en el ejemplo, abriendo un espacio dialógico que posibilita nuevas interpretaciones ya sea por parte del mismo autor del comentario o bien de los propios lectores.

El distanciamiento de los autores con las partes involucradas en el caso comentado es interesante. El autor no solo se distancia de los demandantes o de los demandados, sino

\footnotetext{
${ }^{4}$ En este y todos los ejemplos utilizamos la siguiente nomenclatura: letras ennegrecidas junto con cursivas para los atenuadores sobre los cuales llamamos la atención, cursivas para otros atenuadores presentes en el texto y subrayado para informaciones que resultan cruciales en el funcionamiento de los atenuadores y sobre las cuales también nos referimos en su explicación.
} 
también de las instituciones que también frecuenta en tanto profesional del área y que tienen por cierto un valor simbólico. En este sentido, la voz autoral aboga por representarse a sí misma como neutral, reclamando por tanto una imagen de estatus y justicia (cfr. Spencer-Oatey, 2007) al establecerse como un observador íntegro e imparcial del juicio.

\subsection{Interpretaciones derivadas del análisis jurisprudencial}

El aspecto reflexivo de los comentarios de jurisprudencia se relaciona con dos actividades que se realizan en tal género discursivo: comentar críticamente las obras jurídicas o el accionar de miembros de la comunidad en el contexto de la sentencia declarada; y ofrecer interpretaciones o análisis que deriven de la misma revisión realizada. Este último caso suele ser más frecuente cuando se analizan varias sentencias y usualmente dicen relación con la identificación de discrepancias, vacíos doctrinarios o cambios interpretativos de la norma.

Con respecto a este último caso, en nuestro corpus hemos identificado casos con presencia de atenuación. Los siguientes son ejemplos:

(4) La explicación se encontraría en el hecho de que el tribunal no tuvo por acreditado que el establecimiento educacional hubiera tenido conocimiento de las necesidades especiales de las alumnas al momento de admitirlas, motivo por el cual el demandante dedujo recurso de apelación ante la Corte de Apelaciones de Santiago (CJ_002_19_127).

(5) Miradas las cosas desde esta perspectiva, pareciera que la tutela por publicidad engañosa puede reconducirse a la fase precontractual (nulidad relativa e indemnización complementaria a ella), a la fase contractual (medios de tutela por incumplimiento) o simplemente a la responsabilidad civil extracontractual (indemnización de daños) (CJ_003_18_65).

En (4) el comentarista dilucida una causa que explicaría la determinación del tribunal, mientras que en (5) su autor concluye un sistema de opciones relativo a la afección de la publicidad engañosa. Ambos casos corresponden a interpretaciones elaboradas por la voz autorial, por lo que no son meros reportes de cómo ocurrieron las cosas ni tampoco de cómo otras personas interpretaron los eventos o normas. Por esta razón, la atenuación en estos ejemplos tiene por objeto disminuir la certeza que se tiene sobre tales conclusiones.

En el corpus revisado es frecuente que estas atenuaciones se refuercen por medio de otros atenuadores que funcionan solidariamente (cfr. Villalba, 2018) para reforzar la interpretación. Ilustramos en los ejemplos (6-8) estos casos:

(6) En mi opinión y siguiendo a un importante sector de la doctrina, creo que [el criterio que prima] es el extracontractual, ya que no existe un vínculo jurídico entre la empresa principal y los trabajadores de la contratista (CJ_001_15_63).

(7) En este punto creo, al igual que el profesor Corral, "CITA" (CJ_001_15_68).

(8) Creemos que, como ya antes hemos apuntado en otros trabajos sobre la materia, no todo el problema de las indemnizaciones genéricas descansa en las sentencias y sus autores (CJ_014_10_33).

Los principales atenuadores presentes en (6-8) corresponden a verbos modales ("creer") y adicionalmente en (6) la construcción de contracción dialógica "en mi opinión", que refuerza la atenuación de "creo". En los tres casos se utilizan fórmulas de explicación y comparación atenuantes que aluden a autoridades académicas, subrayadas en los ejemplos. Estas 
últimas son interesantes en tanto el refuerzo que producen se asemeja a la intensificación, lo que produce como efecto que el autor da prominencia a que lo que a continuación señalará es su creencia y que, por tanto, se le debe considerar como tal, lo que le sirve a modo de prevención de su imagen; sin embargo, refuerza de modo anticipatorio su interpretación, generando una suerte de 'opinión fundada'.

De esta forma, y siguiendo lo realizado por Figueras (2018) en torno a que los atenuadores se relacionan con imágenes situacionales particulares (cfr. Spencer-Oatey, 2007), los casos (6-8) configuran una imagen de conservadurismo, concretamente de seguridad y tradición, pues los hablantes prefieren guardar cautela al compartir su posicionamiento ante casos de los cuales ellos no formaron parte. Asimismo, el empleo de atenuadores permitiría no perjudicar la imagen de los colegas, ya sean abogados demandantes o de la parte demandada, así como también de los tribunales. No acusan de procedimientos viciados, por lo que tampoco dudan expresamente de la confiabilidad de las instituciones jurídicas.

Junto con lo anterior, es posible sostener que en estos casos se reclaman también valores asociados con la auto-mejora, al posicionarse como sujetos competentes intelectualmente. Esto se lograría por medio de la inclusión de otras voces, autoridades en la materia que les ocupa, como en (6) y (7), o haciendo alusión a la propia carrera y, por tanto, a reflexiones maduras de la propia voz autoral, como se observa en (8). Casos como estos son interesantes toda vez que tensionan la relación atenuación-intensificación, pues la intertextualidad presente en estos ejemplos sirve a la atenuación al permitirle al autor redirigir la responsabilidad de lo dicho a otros (y también, en consecuencia, de los potenciales perjuicios a la imagen), pero también sirven a la intensificación, pues dan fuerza argumentativa al planteamiento de la voz autoral.

\subsection{Atenuación de los actos asertivos de opinión}

Como precisamos en el apartado 4.2., parte del aspecto reflexivo de los comentarios de jurisprudencia se manifiesta en los comentarios evaluativos que los autores hacen en sus escritos. En efecto, el acto de opinar constituye un acto amenazador para la imagen del opinante. En conversaciones coloquiales esto se ha descrito a propósito de los recursos de explicación y justificación (Guerrero y otros, 2020). Lo anterior se debe a que todo acto asertivo de opinión implica un potencial desacuerdo que podría poner en riesgo la integridad de la imagen de alguno de los participantes, por lo cual el comentario mismo constituye un desencadenante de la atenuación.

Debido a lo anterior, en los comentarios de jurisprudencia se observan opiniones atenuadas cuando aquello que se comenta se corresponde con cosas o procesos, sin que se declare un agente claro que se responsabilice de aquellos. Los siguientes son ejemplos del corpus:

(9) Estimamos que esta evolución del derecho del trabajo chileno es muy importante y fortalece la tutela del trabajador (CJ_007_12_139).

(10) $\boldsymbol{A}$ nuestro juicio, la derogación del precepto impugnado constituiría una decisión muy grave tanto desde la perspectiva formal como sustantiva (CJ_017_10_79). 
Como se puede concluir de (9) y (10), un patrón lingüístico clave en las opiniones es el uso de lenguaje valorativo, sea este positivo, como en «importante» en (9); o negativo, como en "grave» en (10). Es interesante, además, que en estos casos las valoraciones también se encuentren intensificadas, en estos ejemplos por medio del adverbio «muy». Podría pensarse que es la misma intensificación de la cualidad valorativa la que induce a atenuar. Por último, podemos destacar el uso de diversas estrategias para mitigar las opiniones: verbos modales (9), construcciones de contracción dialógica (10) y usos condicionales del verbo (10).

Estas atenuaciones, como se precisó anteriormente, tendrían relación con la necesidad de proteger la imagen propia ante la comunidad disciplinar. Esto, pese a que estas valoraciones no se realicen sobre la acción explícita de algún miembro de esa comunidad. Aun así, tras el proceso de «evolución del derecho del trabajo», en (9), y «derogación del precepto impugnado", en (10), se hallan personas que sí pertenecen a esa comunidad. Concretamente en estos casos, los propios tribunales que fallan en torno a esas materias o, incluso, el propio legislador.

En otro orden de cosas, las opiniones también pueden tener como entidad valorada un agente preciso de la comunidad disciplinar, identificados en los siguientes ejemplos con subrayado:

(11) Una primera cuestión que debería haber consignado el tribunal es qué se entiende por contrato de prestación de servicios educacionales (CJ_002_19_60).

(12) En atención al criterio aquí comentado, la Corte de Apelaciones de Puerto Montt debería haber analizado si la actividad cumplía con las dos restricciones contempladas por el artículo 582 del Código Civil al ejercicio del dominio (CJ_012_19_93).

En (11) la voz autorial cuestiona aquello que no realizaron los tribunales de justicia y en (12) el cuestionamiento recae sobre la Corte de Apelaciones de Puerto Montt. Se trata, entonces, de actores individualizados, aunque colectivos, los que están siendo enjuiciados. Si bien no se evidencia lenguaje valorativo explícito en estos ejemplos, se puede argumentar que en el contenido mismo de la proposición de igual forma se está evaluando un comportamiento. Esto, ya que se aprecia una actitud positiva hacia aquello que no se hizo: haber precisado una definición en (11) y haber analizado el cumplimiento de las restricciones del Código Civil en (12). En consecuencia, la no realización de lo deseable configura por oposición una valoración negativa hacia tales instituciones.

Junto con lo anterior, en el corpus se observan juicios similares a los anteriores, pero con valoraciones inscritas, identificadas en los siguientes ejemplos por medio de subrayado:

(13) Debemos recordar que es la misma Corte quien nos recuerda que esta sentencia se dictó bajo la nueva normativa; sin embargo, la nueva normativa señala: "CITA", en ninguna parte se refiere a los términos usadas por las Cortes en cuestión, por lo cual estimamos que fallaron [los miembros de la Corte] en esta parte a los menos con la nomenclatura usada por las normas ya derogadas (CJ_005_14_23).

(14) En cualquier caso, creemos que la hipertrofia de la responsabilidad extracontractual ha tenido y tiene bastante que ver con el casi nulo reconocimiento del daño moral en sede contractual por parte de la Corte Suprema en el período estudiado en esta investigación (CJ_014_10_10).

(15) Sin embargo, el tribunal sobreargumenta en un doble raciocinio que parece contradictorio (CJ_015_10_63). 
De forma similar a los ejemplos revisados con anterioridad, en (13), (14) y (15) también se hallan agentes claros sobre los cuales recae la valoración negativa. Asimismo, lo enjuiciado corresponde al comportamiento de estas instituciones en relación con su actuar en un juicio particular. En (13) se atenúa por medio del verbo modal «estimamos» la crítica hacia los miembros de la Corte, quienes habrían fallado, en opinión del autor del texto, en el uso de cierta nomenclatura. En (14) se cuestiona a la Corte Suprema por no reconocer el daño moral en sede contractual. Este juicio se mitiga por medio del adverbio "casi», que reconoce un grado de reconocimiento por parte de la institución en comento. Por último, en (15) se señala que el razonamiento del tribunal, si bien no es contradictorio, lo parece.

Los ejemplos (11-15) son interesantes en tanto la potencial amenaza a la propia imagen parece ser más evidente. En esta clina que representan los casos (9-10), (11-12) y (13-15), en este orden, también se identifica con más claridad la amenaza a la imagen pública de un tercero: tribunales o cortes. Estas corresponden a instituciones que cuentan con poder simbólico dentro de la misma área disciplinar, por lo que, al encontrarse en una posición superior en la escala socio-simbólica en comparación con los mismos autores, se torna aún más necesaria la actividad de imagen. En consecuencia, esta comunidad se caracterizaría por un estilo de manejo de conflicto interpersonal que propendería a la integración (alta preocupación tanto por el yo como por el otro) (Rahim, 1992), al menos en interacciones con propósitos académicos.

\section{CONCLUSIONES}

La premisa que orientó este trabajo consistía en que un género altamente disciplinar como el analizado daría cuenta de forma ilustrativa sobre cómo se construye y reconstruye esa comunidad. De esta forma, se utilizaron herramientas de lingüística de corpus para realizar un análisis en específico sobre el funcionamiento de los recursos de atenuación por la estrecha relación que establece este fenómeno pragmático con la (re)construcción de la imagen.

En este contexto, se concluye lo siguiente:

- El uso de atenuadores es frecuente en los comentarios de jurisprudencia. Su uso principalmente tiene por propósito distanciarse de los demás miembros de la comunidad involucrados en el análisis que se realiza (litigantes y jueces institucionalizados) y matizar los juicios que se realizan sobre el comportamiento de las instituciones judiciales.

- Conforme al propósito de presentar conclusiones novedosas en torno a la interpretación de la norma o evolución de la jurisprudencia, los autores también atenúan sus propios aportes. Son frecuentes los casos en que se utilizan varios atenuadores que funcionan solidariamente entre ellos con este fin, incluyendo aquellos que remiten a autoridades en la disciplina. Esto produce que las creencias se presuman fundadas y respaldadas.

- Cuando se valora negativamente a las instituciones judiciales es común el uso de atenuadores. Se destaca que en estos casos la entidad evaluada establece con el 
propio comentarista una relación de asimetría en cuanto a poder simbólico. Por esta razón, los atenuadores suelen atender también a la imagen del otro.

- La principal función que desempeñan los atenuadores en los comentarios de jurisprudencia es salvaguardar la propia imagen con el objeto de prevenir posibles amenazas. En este sentido, se construye una imagen cercana a la universalidad, a la seguridad y al poder, en términos de Spencer-Oatey (2007).

Por último, y en relación con las herramientas de lingüística de corpus utilizadas en este trabajo, es destacable su utilidad para analizar muestras amplias de textos, cuestión que es poco frecuente en descripciones de géneros discursivos. Si bien para el estudio de fenómenos pragmáticos podría ser contraproducente, principalmente por la potencial pérdida de datos, este problema solo provoca que ante grandes muestras se haga necesario revisar detalladamente la preprueba que se realice previo a la explotación misma del corpus.

Del análisis también se destacan otros temas que bien podrían desarrollarse en investigaciones futuras. Entre ellos, destaca principalmente el de la polifuncionalidad pragmática de los usos condicionales del verbo. En la primera parte del proceso fue posible observar la alta frecuencia de este recurso, aunque no todos estos usos eran atenuadores. El aspecto de irrealidad que introducen los condicionales es interesante en el Derecho, en tanto la descripción de las leyes induce a la consideración de casos hipotéticos.

\section{COMENTARIOS DE JURISPRUDENCIA ANALIZADOS}

Barrientos, Marcelo (2010): «Análisis preliminar de la jurisprudencia de la Corte Suprema sobre daños morales en causas por incumplimientos contractuales civiles de los años 2002 a 2007», Revista Chilena de Derecho, 37(1), pp. 163170.

Cerón, Roberto (2015): «Corte Suprema. ROL nº 9.858-2013. Recurso de unificación de jurisprudencia (artículos 183-B y 183-E del Código del Trabajo)», Revista de Derecho, 22(1).

Etcheverry, Leonor (2014): «Derecho de familia, sucesorio y regímenes matrimoniales», Revista Chilena de Derecho Privado, 22.

Gamonal, Sergio (2012): «Evolución del daño moral por término del contrato de trabajo en el derecho chileno", Revista de Derecho de la Pontificia Universidad Católica de Valparaíso, 39, 161-176.

López-Díaz, Patricia (2018): «Obligaciones y responsabilidad civil», Revista Chilena de Derecho Privado, 30.

López-Díaz, Patricia (2019): «Obligaciones y responsabilidad civil», Revista Chilena de Derecho Privado, 33.
Padilla, Ricardo y Ricardo Reveco (2017): "Derecho de la libre competencia», Revista Chilena de Derecho Privado, 28.

Schiele, Carolina y Josefina Tocornal (2010): «Artículo 2329 del Código Civil. La interpretación de presunción por hechos propios existe en la jurisprudencia», Revista Chilena de Derecho, 37(1), pp. 123-139.

Tisné, Jorge (2019): «Categorización de los conflictos vecinales y la improcedencia de invocar autorizaciones administrativas y la observancia de leyes y reglamentos como justificación suficiente para vulnerar derechos de terceros. Comentario a la sentencia de la Corte Suprema, de fecha 15 de marzo de 2018, ROL no 18.218-2017», Revista Chilena de Derecho, 46(1).

Vivanco, Ángela (2010): "Justicia constitucional, libre elección en materia de salud y normativa sobre isapres: un comentario a la reciente jurisprudencia del Tribunal Constitucional», Revista Chilena de Derecho, 37(1), 141-162. 


\section{REFERENCIAS BIBLIOGRÁFICAS}

Albelda, Marta (2016): «Sobre la incidencia de la imagen en la atenuación pragmática», Revista Internacional de Lingüística Iberoamericana, 14(1), pp. 19-32.

Albelda, Marta; Ana María Cestero; Silvana Guerrero y Marta Samper (2020): «Variación sociopragmática y geolectal en el uso de atenuación", Lengua y Habla, 24, pp. 1-53.

Albelda, Marta y Wiltrud Mihatsch, eds. (2017): «Atenuación e intensificación en géneros discursivos»,

Madrid/Frankfurt: Iberoamericana/Vervuert.

Alonso-Almeida, Francisco (2015): "On the mitigating function of modality and evidentiality. Evidence from English and Spanish medical research papers", Intercultural Pragmatics, 15(6), pp. 521-549.

Agüero San Juan, Claudio (2014): «¿Conforman las sentencias penales un género discursivo?», Estudios Filológicos, 53, pp. 7-26.

Aguilar Peña, Paula (2017): «Una propuesta de géneros discursivos escritos del ámbito universitario, jurídico y chileno, orientada a la alfabetización académica de estudiantes de derecho», Perfiles educativos, 39(155), 179192.

Bajtín, Mijail (1985): Estética de la creación verbal, México: Siglo XXI.

Bazerman, Charles (1988): Shaping Knowledge. The genre and activity of the experimental article in science, Wisconsin: University of Wisconsin Press.

Bazerman, Charles (2012): Géneros textuales, tipificación y actividad, Puebla: Benemérita Universidad Autónoma de Puebla.

Briz, Antonio (2001): El español coloquial en la conversación: esbozo de pragmagramática, Barcelona: Ariel.

Briz, Antonio (2017): «Una propuesta funcional para el análisis de la estrategia intensificadora en la conversación coloquial», en Marta Albelda y Wiltrud Mihatsch (eds.), Atenuación e intensificación en géneros discursivos, Madrid/Frankfurt: Iberoamericana/Vervuert, pp. 43-67.

Briz, Antonio y Marta Albelda (2013): «Una propuesta teórica y metodológica para el análisis de la atenuación lingüística en español y portugués. La base de un proyecto en común (ES.POR.ATENUACIÓN)", Onomázein, 27(2), pp. 288-319.

Caffi, Claudia (1999): «On mitigation», Journal of Pragmatics, 31, pp. 881-909.
Carlino, Paula (2006): Escribir, leer y aprender en la universidad, Argentina: Fondo de Cultura económica.

Cestero, Ana María (2017): «La atenuación en el habla de Madrid: Patrones sociopragmáticos», RILCE, 33(1), pp. 57-86.

Cestero, Ana María (2020): «Uses and resources of mitigation, in contrast», Spanish in Context, 17(2), pp. 362-383.

Cestero, Ana María y Marta Albelda (2012): «La atenuación lingüística como fenómeno variable», Oralia, 15, pp. 77-124.

Cestero, Ana María y Marta Albelda (2020): «Estudio de variación en el uso de atenuación I: Hacia una descripción de patrones dialectales y sociolectales de la atenuación en español», Signos, 53(104), pp. 935-961.

Cestero, Ana María y Lidia Rodríguez (2021): Guía PRESEEA de estudio de la atenuación, Alcalá de Henares: Universidad de Alcalá.

Conley, John y William O'Barr (2005): Just words: Law, language, and power, Chicago/Londres: University of Chicago Press.

Fairclough, Norman (2013): «Language, ideology and power», en Critical Discourse Analysis. The Critical Study of Language, Londres/Nueva York: Routledge.

Figueras, Carolina (2018): "Atenuación, género discursivo e imagen", Spanish in Context, 15(2), pp. 258-280.

Goffman, Erving (1959): The Presentation of Self in Everyday life, New York: Anchor Books.

Goffman, Erving (1967): Interactional Ritual: Essays on Face-To-Face Behavior, New York: Pantheon Books.

Goffman, Erving (1974): Frame Analysis: An Essay on the Organization of Experience, New York: Harper and Row.

Goffman, Erving (1981): Forms of Talk, Philadelphia: University of Pennsylvania Press.

González, Virginia y Amparo García (2017): «Atenuación e intensificación: estrategias pragmáticas del rechazo en respuestas a invitaciones en redes sociales en línea", en Marta Albelda y Wiltrud Mihatsch (eds.), Atenuación e intensificación en géneros discursivos, Madrid/Frankfurt: Iberoamericana/Vervuert, pp. 187-204.

González Riffo, Javier y Silvana Guerrero (2017): «Estrategias de atenuación en narraciones conversacionales», Lengua y Habla, 21, pp. 29-44. 
Guerrero, Silvana; Consuelo Gajardo; Javier González Riffo y Antonia Reyes (2020): «"Lo que pasa es que la política se ha puesto farandulera": justificaciones atenuantes de aserciones de opinión en el corpus PRESEEA de Santiago de Chile», Literatura y Lingüística, 42, pp. 247-273.

Haas, Christina (1994): «Learning to read biology: One student's rhetorical development in college», Written Communication, 11(1), pp. 43-84.

Hyland, Ken (1996): "Talking to the academy: Forms of hedging in science research articles", Written Communication, 13(2), pp. 251-281.

Hyland, Ken (1998): Hedging in scientific research articles, Ámsterdam: John Benjamins.

Hyland, Ken (2005): «Stance and engagement: a model of interaction in academic discourse", Discourse studies, 7, pp. 173-192.

Martin, James y David Rose (2008): Genre relations: mapping culture, Londres: Equinox.

Martín-Martín, Pedro (2008): «The mitigation of scientific claims in research papers: A comparative study", International Journal of English Studies, 8(2), pp. 133-152.

Meyer-Hermann, Reinhard (1988): «Atenuación e intensificación (análisis pragmático de sus formas y funciones en español hablado)", Anuario de Estudios Afilológicos, 11, pp. 275290.

Monjour, Alf (2017): «“Cómo que las 6:45? ¡Si a esa hora es cuando salía el tren!" “Se sabe algo de la reunión?, era a las 11, no?" Usos dislocados del imperfecto español como estrategias de atenuación e intensificación», en Marta Albelda y Wiltrud Mihatsch (eds.),
Atenuación e intensificación en géneros discursivos, Madrid/Frankfurt: Iberoamericana/Vervuert.

Morales, Oscar; Daniel Cassany y Carolina González (2007): «La atenuación en artículos de revisión odontológicos en español: estudio exploratorio», Ibérica, 14, pp. 33-57.

Rahim, Afzalur (1992): Managing Conflict in Organizations, Westpot: Praeger.

Samper, Marta (2018): «Un cambio en tiempo real: La atenuación entre hablantes universitarios de Las Palmas de Gran Canaria», RILCE, 34(3), pp. 1259-1279.

Spencer-Oatey, Helen (2007): «Theories of identity and the analysis of face», Journal of Pragmatics, 39, 639-656.

Swales, John (1990): Genre analysis: English in academic and research settings, Cambridge: Cambridge University Press.

Swales, John (2004): Research genres: Exploration and applications, Nueva York: Cambridge University Press.

Tolchinsky, Liliana, coord. (2013): La escritura académica a través de las disciplinas, Barcelona: Octaedro.

Villalba, Cristina (2012): «El valor atenuante de la impersonalidad en los juicios orales", Anuario de Lingüística Hispánica, XXVIII, 117-132.

Villalba, Cristina (2016): Actividades de imagen, atenuación e impersonalidad en los juicios orales, tesis doctoral. Valencia: Universitat de València.

Villalba, Cristina (2018): «Atenuación: algunas claves metodológicas para su análisis». Normas, 8(1), pp. 306- 316. 